\title{
A Noção de Ontologias Múltiplas e suas Consequências Políticas ${ }^{1}$
}

\author{
Iara Maria de Almeida Souza
}

Faculdade de Filosofia e Ciências Humanas, Salvador, Bahia, Brasil.

E-mail:imas@ufba.brr 


\section{Resumo}

É possível observar hoje nas ciências sociais um interesse crescente pela ontologia. Se boa parte da agenda clássica da disciplina estava situada no campo da epistemologia, centrada na noção de representação, a agenda atual em grande medida se define por uma preocupação em entender não visões de mundo, mas as realidades ou os mundos em que se está imerso. Segundo Marres, a virada ontológica nesta disciplina compreende níveis distintos de reflexão. No primeiro nível, ontologia se refere à explicitação dos pressupostos metateóricos acerca de quais entidades constituem a realidade e quais são as relações entre elas. Em outro nível se situam os autores cuja abordagem é rotulada por Marres de ontologia empírica, ou seja, que a pensam como fenômeno empírico ou acontecimento. Procura-se explorar neste nível as associações por meio das quais diferentes entidades vêm a ser no mundo, já que a própria realidade é vista como múltipla e fluida. A proposta deste artigo é discutir mais detidamente este segundo nível da ontologia, em especial a noção de ontologia múltipla formulada por Mol, explicitando sua compreensão das consequências políticas desta abordagem.

Palavras-chave: Ontologia Múltipla. Ontologia Política. Annemarie Mol.
Abstract

There is in Social Sciences an increasing interest in ontology. The classic agenda of the disciplines was directed to epistemology and the notion of representation the contemporary one, instead, is concerned with realities and worlds in which we do live. According to Marres an ontological turn in Anthropology has distinct levels of reflection. In the first, ontology refers to the act of making clear the theoretical assumptions about what exist in the world. The second level corresponds to an empirical ontology. At this ontology is taken as an empirical phenomenon or event in which entities come to be in the world, and the reality is seen as multiple and fluid. This article aims at examining this second level, the notion of Annemarie Mol's multiples ontologies in particular, and then seeks to explore its political consequences.

Keywords: Multiple Ontologies. Political Ontology. Annemarie Mol. 


\section{Introdução}

1 s ciências sociais vivem no presente uma virada ontológica", tal - afirmação, embora encontre defensores, é certamente controversa. Tomar uma posição a favor ou contra a existência deste fenômeno, entretanto, talvez não seja o modo mais interessante de lidar com a questão. Se este fosse o caso, seria recomendável realizar um amplo mapeamento do que tem sido discutido e publicado sobre o tema para alcançar uma visão ponderada do panorama na teoria social, a fim de pôr um ponto final à controvérsia. Não é esta a proposta deste artigo. O que interessa aqui não é afirmar ou negar a "virada ontológica". A ideia é discutir, reconhecendo a existência de um crescente interesse na antropologia pelo problema ontológico, a proposta de ontologias múltiplas formulada por Annemarie Mol, explorando mais detidamente as consequências éticas e políticas de uma teoria que afirma a multiplicação da realidade em distintas versões, ao invés de sustentar, como é mais usual, a existência de uma única realidade representada de modos variados. Vê-se aqui um dos pontos de disputa que surge quando se fala em ontologia: a realidade é única? A ontologia pode ser múltipla?

A existência de concepções variadas acerca da ontologia é organizada por Marres (2009) em um esquema que permite situálas de acordo com seus distintos níveis de reflexão. Segundo ela, em um primeiro nível, mais clássico e conceitual, ontologia se refere à explicitação dos pressupostos metateóricos acerca de quais são as entidades que constituem o mundo ou a realidade e as relações sociais entre elas (Marres, 2009, p. 126). Ao invés de procurar responder à pergunta sobre o modo como se conhece o mundo (interrogação epis- 
temológica por excelência), a ontologia busca esclarecer e explicitar a questão acerca da natureza do ser e/ou dos distintos modos de ser que se encontram no mundo. Tome-se como exemplo a ontologia heideggeriana de "Ser e Tempo", que influencia diretamente autores das ciências sociais como Giddens e Bourdieu. Nesta obra, Heidegger (1988) propõe uma retomada da questão do ser a partir do Dasein (presença ou ser-no-mundo), um ente que ao existir põe o ser em questão, e explicita quais são os existenciais, ou seja, seus momentos constitutivos: mundo, compreensão, disposição, cuidado etc. Assim como a ontologia heideggeriana se propõe como tarefa explicitar os componentes estruturais do fenômeno unitário do ser-no-mundo, uma das questões centrais nas abordagens herdeiras de Ser e Tempo é o esclarecimento dos princípios ou estruturas que orientam a ação humana (sua cumplicidade com o mundo, o envolvimento em contextos de prática, a temporalidade que lhe é peculiar). Vale notar que essa ontologia não só define como hierarquiza as diferentes entidades encontradas no mundo. Entes que não existem no modo da compreensão também povoam o mundo habitado pelo Dasein. Para Heidegger (1988), entretanto, é o Dasein que fornece a chave para o ser destes entes ${ }^{2}$.

Marres qualifica tal abordagem, que busca elaborar uma espécie de gramática da realidade social, como uma abordagem epistêmica à ontologia, pois afirma que o discurso teórico é o plano mais relevante no qual a existência das entidades é posta. A radicalização da noção de ontologia - na direção de uma ontologia empírica - é em certa medida uma resposta a essa concepção.

O segundo nível da reflexão ontológica no esquema proposto por Marres é justamente aquele que ela chama de "ontologia empírica", pois considera não apenas o plano teórico, mas as práticas e eventos a partir dos quais novas entidades sociais emergem. Autores alinhados com essa perspectiva, como Latour (2004; 2005), Mol (1999; 2002) e Stengers (2002), influenciados em grande medida por Whitehead, exploram as associações por meio das quais diferentes entidades vêm a ser no mundo. Há entre eles uma preocupação em marcar distância frente à concepção epistemológica por conta da demasiada importância 
atribuída por esta ao modo como se conhece ou se representa a realidade, afirmada no singular. Com efeito, há mesmo recusa direta à ideia de que há uma única realidade e muitas perspectivas (ou representações) sobre ela. Para a ontologia empírica é a própria realidade que é múltipla e fluida; a atenção se volta, então, para as práticas, discursos, eventos que se constituem em ocasião para a articulação de novas entidades, que são sempre situadas em algum lugar e tempo. Diferente da ontologia "clássica", não há qualquer princípio extra-histórico que explique a existência destas entidades ou que possa ser invocado para defini-las ou estabelecer sua essência.

Marres, provavelmente, por conta de seus interesses de pesquisa, cita autores mais ligados aos estudos de ciência e tecnologia, mas este renovado interesse por ontologia se encontra também presente na teoria antropológica. As agendas emergentes em ambas as áreas produzem mudanças de ênfase e interesse, por exemplo, noções como as de performatividade ou prática ganham relevância em lugar de representação; a ontologia prática, por conseguinte, se sobrepõe à epistemologia; os relatos sobre a agência de humanos e não humanos substitui uma compreensão centrada nas interpretações produzidas por sujeitos ou por sociedades constituídas exclusivamente por humanos. Não são poucas as reações críticas suscitadas por essas mudanças de ênfase. De um lado, as resistências se dirigem a um suposto enfraquecimento do vigor crítico, ao desengajamento de projetos claramente emancipatórios e, consequentemente, à perda de relevância política. Tudo isso, do ponto de vista dos críticos, seria resultado da tomada de uma posição relativista - correlata à noção de realidades múltiplas (Jensen, 2004). Além disso, se argumenta que os aspectos éticos e normativos envolvendo sujeitos e grupos humanos seriam negligenciados por causa do nivelamento/simetrização entre agências de humanos e não humanos (Jensen, 2004). Sem dúvida, como pretendo argumentar aqui, as acusações de desinteresse pela ética e política não se sustentam, mas é preciso tentar tornar mais claros quais são os contornos de uma nova atitude ética e política assentada em uma concepção de ontologias múltiplas. Tendo isso em conta, o interesse principal neste artigo é explorar essas questões a partir do pensamento 
de Anemarie Mol, cuja proposta, que parece endereçar diretamente as críticas mencionadas anteriormente, recebe justamente a designação de ontologia política. Ela pretende unir, com esse conceito, ontologia - algo que na interpretação mais usual lida com realidades fixas - e política, cuja compreensão frequentemente remete àquilo não é dado, que precisa ser construído e negociado. Contudo, antes de apresentar sua formulação, pretendo expor brevemente o modo como a questão da ontologia empírica tem sido mais recentemente recuperada nos estudos sobre ciência, com os quais a proposta de ontologia política de Mol tem um vínculo bastante estreito, e na antropologia.

\section{2 "Virada Ontológica" nos Estudos de Ciência e Tecnologia}

A virada ontológica nos estudos de ciência e tecnologia, bem como na teoria antropológica como se verá em seguida, envolve uma rejeição à abordagem epistemológica, à hegemonia da representação e à concepção de ciência como uma esfera bem delimitada, autônoma, dotada de coerência interna que se relacionaria com outras esferas situadas em seu exterior, como a política. Além disso, ela também envolve uma compreensão de mundo povoado por múltiplas e diferenciadas formas de agência que não se restringem à ação humana. Veja-se, de modo sucinto, como a questão ontológica passa ter mais peso neste campo de estudos.

As ciências sociais, quando passam a tomar a ciência como objeto de interesse, de início não abordam diretamente os conteúdos das ciências, mas os aspectos normativos do comportamento dos cientistas, as hierarquias da carreira, a influência de certos aspectos culturais sobre o desenvolvimento de instituições acadêmicas etc. Ou seja, o social era uma esfera exterior à ciência e não influenciava o conhecimento propriamente dito, mas apenas aspectos superficiais envolvidos na sua institucionalização. Com frequência, a posição das ciências como modelo de racionalidade era mantida, bem como a ideia de que o conhecimento resultava do uso metódico da razão que permitia ao cientista representar, de modo adequado, os fenômenos dados na natureza, que era considerada como matéria bruta e dada. 
O realismo ingênuo implicado em tal posição foi questionado de vários modos, em especial a partir da segunda metade da década de 1970 do século XX, quando começaram a emergir as diferentes posições construcionistas no campo de estudos de ciência e tecnologia, que mostravam o mundo natural como resultado de uma construção histórica e afirmavam fortemente a presença do social e do político no conhecimento científico. As verdades que a ciência afirmava sobre a natureza não eram, portanto, alheias aos valores, interesses, ideologias, lutas por recursos etc. Deve-se a Bloor (1991) uma das ideias-chave da crítica ao realismo ingênuo: a noção de simetria, que implica na adoção por parte dos cientistas sociais de uma atitude de abstenção com relação ao que é considerado veraz ou falso na ciência da natureza, e envolve também uma busca de explicação causal dada nos mesmos termos para o erro ou a verdade. O ponto mais forte de seu argumento é: não se pode ceder à crença pueril de que a verdade está referida à natureza, enquanto a incorreção ou o engano estão referidos ao social. O contexto social permeia toda a ciência, portanto, é necessário que se trate de modo simétrico seus vencedores e vencidos.

As etnografias de laboratório ao mesmo tempo em que reforçaram a crítica ao realismo ingênuo, ao contestarem a ideia de que o empreendimento científico pode ser pensado em termos meramente descritivos (Latour; Woolgar, 1997; Knorr-Cetina, 1983, 1999; Lynch, 1991 ) dão um passo na direção da ontologia, ao privilegiar os contextos práticos de produção de ciência e tecnologia. É crucial para isso a atenção concedida em tais estudos aos processos e entidade materiais envolvidos no fazer científico. Há um deslocamento do interesse das teorias e ideias presentes na ciência, para as associações entre humanos e não humanos envolvidos em sua prática, ao mesmo tempo em que se produz uma desestabilização da divisão moderna entre natureza e sociedade ou cultura (Pickering, 1995; Knorr-Cetina, 1995; Callon, 1986; Latour, 1999).

O passo inicial para a virada ontológica foi dado: as ciências são conhecidas a partir do modo como se fazem na prática. Há uma mudança de um idioma representacional para um idioma performativo nos estudos de ciência e tecnologia, e, concomitantemente, um deslo- 
camento do interesse em epistemologia para uma preocupação com os modos através dos quais as realidades são construídas, ou seja, como ganham forma na ação (Pickering, 1995). Se o idioma representacional caracteriza a ciência antes de tudo como uma atividade que mapeia, espelha e corresponde ao mundo como ele realmente é, o idioma performativo envolve uma concepção de que o mundo é pleno de agência, a própria ação, portanto, já não é mais compreendida como algo que diz respeito apenas a agentes humanos. Além disso, atividades tais como observar ou representar não são vistas como distintas de intervir ou construir; ao invés disso, são consideradas como modos específicos de intervir e construir a realidade (Jensen, 2004).

Qual seria, então, a ontologia que permite falar simultaneamente de realidades e construção? Como combinar noções de existência e agência ao mesmo tempo, sem propor um retorno à concepção que credita à natureza um caráter dado e objetivo? Uma ontologia que procura encontrar um caminho alternativo à visão dicotômica que impõe a escolha entre, de um lado, a versão positivista dos fatos, para a qual a matéria é um dado bruto do mundo, sempre a mesma em qualquer lugar, e, de outro, a versão desconstrucionista, segundo a qual aquilo a que se tem acesso é apenas à plasticidade sem fim do significado, sempre fragmentado e perspectivado. A posição neorrealista rejeita os termos dessa escolha - entre positivismo e desconstrucionismo - e afirma a existência de coisas que são simultaneamente materiais e significativas; possuem plasticidade, mas também constrangem e limitam as práticas; nesta perspectiva as coisas não são inertes, possuem forças, trajetórias, tendências, propensões, recalcitrância e trazem uma margem de indeterminação que não nos permite fixar de antemão tudo que se pode esperar delas (Braun; Whatmore, 2010). O materialismo vinculado a essa posição é relacional, não confunde os objetos da ciência com a coisa em si, nem os reduz a projeções da mente do sujeito, mas pensa a manifestação e expressão de coisas em campo de relações envolvendo agentes heterogêneos.

Uma das consequências da entrada em cena nos estudos de ciência e tecnologia da agência de não humanos é que isto produz uma diferença, o mundo se torna mais complexo e o antropocentrismo é posto em questão, sem dúvida. Mas talvez isso não seja tão difícil de 
aceitar quanto a inclusão no escopo de não humanos que compõem o nosso mundo aquelas entidades que não encontram seu berço na ciência e são consideradas em várias instâncias como seres imaginários tais como deuses, djins, espíritos, Santa Maria (Stengers, 2010). Para tratar dessa questão, a proposta de múltiplas ontologias que emerge na antropologia talvez possa nos oferecer meios para pensar melhor.

\section{A "Virada Ontológica" na Antropologia}

De acordo com Jensen (2004), a preocupação com ontologia emergiu de modo mais ou menos simultâneo nos campo dos estudos sobre ciência e tecnologia e na antropologia. No primeiro, ontologia é discutida desde meados da década 1990 nos trabalhos de Bruno Latour, Annemarie Mol, Andrew Pickering enquanto na última, a inspiraçãochave vem de Marilyn Strathern, Roy Wagner e Eduardo Viveiros de Castro. Para ele a emergência da questão da ontologia nesses campos não é fortuita, dado que os autores mencionados compartilham certas genealogias e são afiliados de modos diversos e complexos. Tampouco, para ele, as duas visões de ontologia seriam antitéticas ou incomensuráveis. Em ambos os casos, a noção de ontologia recusa a prioridade à representação, enfatizando as práticas e os modos como o mundo se faz diferentemente. Também ambas desestabilizam as divisões modernas entre humanos e não humanos, entre animado e inanimado, natureza e cultura.

Veja-se então como se inicia a discussão sobre ontologia na antropologia. O uso do termo ontologias, de acordo com Candea (Carrithers et al., 2008), aparece com mais força na antropologia quando se difunde na disciplina a sensação de que a palavra cultura deixou de desempenhar a sua função por não levar suficientemente a sério a alteridade e, por conseguinte, por ter perdido seu vigor analítico e retórico. Daí a necessidade da palavra ontologia, na verdade ontologias, dita no plural para acentuar a existência de diferentes mundos e realidades.

Por que cultura já não se prestaria mais à função de apontar para a diversidade, quando de início ela trazia uma atitude anti-essencialista, que visava justamente desafiar uma concepção naturalista de homem 
e de sociedade? Em parte o problema reside no fato de que o termo cultura foi frequentemente usado para mostrar as perspectivas de grupos humanos sobre um mundo único. Por exemplo, se supunha que havia uma natureza no singular, representada de modos distintos por diferentes culturas. Tal concepção era sustentada a despeito de inúmeras culturas sequer reconhecerem a separação entre natureza e cultura. Uma entidade como Pachamama não se enquadra bem em qualquer dos pólos da divisão ocidental moderna de sujeito e objeto, natureza e cultura. No idioma representacional ela seria considerada como um símbolo estratégico no campo da política étnica contra a política colonial, ou ainda poderia ser considerada como uma insígnia na luta por recursos e/ou uma metáfora mobilizada para salvar o meio ambiente da destruição advinda do industrialismo. Assim, a afirmação de que pachamama é um ser ativo e senciente não seria ouvida a não ser nesse registro do símbolo, metáfora, insígnia e, portanto, não considerada seriamente (Blaser, 2014).

É justamente essa visão que o termo ontologia visa contestar ao romper com o idioma representacional. Uma abordagem ontológica leva as coisas encontradas no campo seriamente sem explicá-las ou contextualizá-las. O recurso à palavra ontologia vem da suspeita de que falar de diferença cultural não é diferente o bastante, ou alternativamente, que diferença cultural foi reduzida pelos críticos culturais a mero efeito da instrumentalidade política (Henare; Holbraad; Wastell, 2005). Como observa Viveiros de Castro (2003, p. 18):

A noção de ontologia tem seus riscos [...] contudo, eu penso que a linguagem da ontologia é importante por uma razão tática específica. Ela age como uma medida contrária ao artifício desrealizante frequentemente usado contra o pensamento nativo, que converte seus pensamentos em uma espécie de fantasia, ao reduzilo às dimensões de uma forma de conhecimento ou representação, que é uma epistemologia ou visão de mundo.

Contudo, nem sempre é fácil compreender em que medida ontologia efetivamente difere radicalmente do termo cultura. Segundo Blaser (2014), frequentemente, no contexto da pesquisa indígena, a 
palavra ontologia é usada para assinalar a diferença entre um dado grupo indígena e os agentes da modernização/colonização ocidental. Nesse caso, o sentido do termo parece ser capturado por uma definição de dicionário, pois qualquer modo de compreensão do mundo inevitavelmente apresenta pressupostos (implícitos ou explícitos) sobre que tipos de coisas existem ou podem existir e quais são suas condições de existência, relações de dependência etc. Esse inventário, por vezes, é chamado de ontologia, mas uma ontologia que se assemelha demais ao modo convencional de considerar o "Outro", essencializando-o e homogeneizando as diferenças em sua oposição ao Ocidente (Blaser, 2014). Por isso, é importante não reduzir a questão da ontologia a esse inventário, nem tratá-la como mero pressuposto teórico. O sentido propriamente antropológico de ontologia envolve uma atenção ao modo como a multiplicidade de formas de existência é atuada em práticas concretas e ao modo como pessoas e coisas podem se alterar por elas mesmas, podem existir de outros modos (Holbraad; Pedersen; Viveiros de Castro, 2014). É a isso que os autores dão o nome de política ontológica. Nesse caso, ontologia é pensada também como uma ferramenta que não apenas descreve a realidade, mas a atua efetivamente, pois incorpora afirmativamente aos relatos etnográficos as possibilidades das coisas existirem de outros modos. Isso quer dizer que assim como há diversos mundos, há múltiplas ontologias, inclusive porque os mundos se desdobram em outros modos possíveis.

Talvez essa seja uma diferença a se considerar entre a proposta de ontologias múltiplas de Mol e as múltiplas ontologias da antropologia. Neste último caso, se está falando de mundos diversos, ainda que passíveis de conexões parciais. Mol, entretanto, trata de versões diferentes de uma entidade que é dita no singular. Em comum as duas abordagens tratam ontologia como profundamente enraizada na etnografia.

\section{Múltiplas Ontologias e Política Ontológica}

Nesta seção em que se explicita mais diretamente a posição de Annemarie Mol, sua definição de ontologias múltiplas e política ontológica, me deterei principalmente em seu livro de 2002, “The Body 
Multiple". Nesta obra, ela explora diferentes versões de uma doença, a aterosclerose. Mas não se trata, como enfatiza, de mostrar quais são as distintas perspectivas sobre uma doença única. Se assim fosse ter-se-ía um objeto unificado ao qual diferentes olhares se dirigiriam, assim, o que se multiplicaria seriam os pontos de observação e não a realidade. O argumento defendido por Mol é que a própria doença é múltipla, sua realidade que se multiplica a partir dos diferentes modos como ela é atuada (enacted) em distintos contextos de prática em um hospital na Holanda. Embora, ela apresente uma etnografia da doença, seu trabalho, é definido por ela como filosofia empírica. Por isso, ao invés de apresentar uma discussão teórica depurada de seu conteúdo etnográfico, opta-se por tratar de sua proposta mantendo a discussão próxima do contexto de pesquisa no qual ela está envolvida.

Influenciada pelos estudos de ciência e em especial pela teoria ator-rede, mas em diálogo com a antropologia médica, Mol coloca a esta última tradição o seguinte problema: o que é a realidade da doença? Para ela, há dois momentos claros na resposta a essa pergunta dentro da antropologia médica. Primeiramente, se considerava que havia um substrato biológico comum à humanidade, a doença (disease) corresponderia a uma entidade natural e objetiva dada em um mundo de fatos e seria recoberta de significados de acordo com as diferentes culturas, perspectivas ou visões de mundo (reunidas sob o rótulo de illness). Em um segundo momento, essa abordagem, criticada pela assunção ingênua dos pressupostos da ciência médica ocidental, foi substituída por uma posição que não mais aceitava a existência de uma realidade subjacente às diferenças de significados. A própria noção da existência do corpo ou da doença como entidades objetivas e naturais seria ela mesma mais uma perspectiva. A pergunta sobre a realidade da doença não mais faz sentido neste caso, ao contrário, já que não havia mais uma natureza à qual se apelar, o ponto era justamente desnaturalizar e desconstruir a doença como entidade biológica. O problema, segundo Mol, é que neste caso a doença em sua realidade permanece intocada, o corpo físico é deixado de lado e fica-se apenas com interpretações. Buscando uma saída para esse perspectivismo, Mol propõe um retorno à realidade, tal qual ela é atuada na prática, em suas praticalidades, materialidades e associações de elementos 
heterogêneos. Como há diversas formas de atuação da doença, há também várias doenças.

O problema que Mol tem que enfrentar é como, sendo múltipla, a doença não se fragmenta em muitas entidades distintas, ao contrário, as práticas são consideradas como diferentes versões de uma mesma doença. Segundo ela, a doença é mais que uma e menos que várias. Como isso é possível? Mol não dá uma resposta abstrata a esta questão. Assim como a doença é sempre atuada em uma prática, a sua unidade não é prévia, mas resulta de um trabalho, é uma realização. Portanto, a resposta a essa pergunta só pode ser encontrada na prática e na atenção que deve ser dados aos modos de coexistência das distintas versões.

A doença na clínica é atuada como dor ao caminhar e realizada pela conversação entre médico e paciente, além de outros componentes da situação. Na patologia é atuada como um ateroma aderido às artérias e visto no microscópio. Na cirurgia como uma obstrução em uma artéria que precisa receber algum tipo de intervenção de modo a fazer com que o sangue volte a fluir. Na medicina interna é um processo, que evolui ao longo do tempo, de oclusão das artérias e se completa com sua obstrução. Na epidemiologia, como um risco à saúde da população e calculada a partir de registros quantificados e calculados. E há ainda outras versões da aterosclerose, bem como várias técnicas através das quais a aterosclerose se faz visível, cognoscível, audível. Nenhuma delas se faz apenas com a participação de humanos, todas são híbridas, algumas delas se fazem com bisturi, aparelhos de raios-X, microscópio, tensiômetros, artigos publicados etc. Uma não exclui a outra, elas podem se coordenar, se alinhar em uma direção, por exemplo, quando o relato de dor do paciente é compatível com as imagens mostradas no exame e na tomada de pressão arterial da perna quando comparada com a pressão tomada no braço. Mas elas também podem se chocar, se suceder, ser adicionadas uma a outra etc. O que importa para ela justamente é explorar as formas de coexistência destas diferentes da doença.

Diferente de Latour, que tende a enfatizar a existência de controvérsia acerca de entidades que se convertem em questões de interesse e procura acompanhar o destino destes objetos até o encerramento da controvérsia, para Mol as diferenças podem conviver 
sem que isso implique necessariamente na existência de um fato controverso a espera de seu fechamento. As diferentes versões da doença, não são necessariamente controversas, elas estabelecem relações distintas entre si, coexistem.

Na proposta apresentada por Mol, mudar da compreensão do objeto como o ponto focal de várias perspectivas para seguir o modo como suas versões são atuadas em uma variedade de práticas, implica em uma mudança da pergunta acerca de como a ciência representa seus objetos, para interrogar como ela intervém. Isto significa que o que interessa aqui prioritariamente já não é o conhecimento, como uma afirmação verdadeira sobre a realidade, mas como uma prática que interfere em outras práticas. O conhecimento, portanto, participa da realidade, não é exterior a ela.

Uma consequência que se pode extrair disso é, de acordo com Mol, que há uma mudança na relação entre as ciências. Não há mais fronteiras tão claras entre as disciplinas, traçada pelos objetos que pertencem a cada uma delas. Se nos mantivéssemos no modelo mais tradicional, das delimitações bem estabelecidas, só a medicina poderia falar sobre doença, as ciências sociais falariam talvez dos aspectos psicossociais da doença, ou seja, se deteria na camada de significados (superficial) que recobre o objeto. Se esta divisão fosse aceita, seria preciso admitir também que os objetos precedem as ciências, além de tomar como pressuposto a separação entre corpo e mente, cultura e natureza, desease e illness, entre sociologia e biologia. Na prática os fenômenos não pertencem a ordens separadas. Se voltarmos à aterosclerose e suas versões, a decisão sobre tratamento tem a ver com a extensão da estenose, mas também com a extensão de dias de permanência no hospital. Não faz sentido, na prática, dizer que ambas pertencem a duas camadas diferentes de realidade. As duas são relevantes e reconhecidas conjuntamente no hospital. Portanto, o que as diferentes ciências têm a oferecer não são vários objetos, mas distintas realizações, ou técnicos de intervenção e, com efeito, diferentes métodos.

Nesse livro, ela argumenta que distintas praticalidades (de pesquisa, diagnóstico e tratamento) endereçam uma aterosclerose ligeiramente diferente. Essa ideia não é estranha ao hospital, os próprios 
médicos, por exemplo, reconhecem este fato quando duas atuações divergem, se aquilo que acontece na clínica não se alinha com o resultado de exames, eles podem deixar de considerar a imagem como uma representação do que se encontra ao interior das artérias e atentar para o modo como as imagens são produzidas para explicar porque se deu o choque entre as duas versões (o exame pode não ter sido bem realizado ou há uma possibilidade de um determinado equipamento produzir distorções sistematicamente). Os profissionais possuem dois repertórios, podem por as praticalidades entre parênteses - para ter um desempenho confiante - ou manter as praticalidades da atuação da doença visíveis de modo que eles possam duvidar. Eles podem ceder espaço a outras atuações da realidade, outras versões da doença a ser diagnosticada ou tratada, ou fechar as alternativas de modo a seguir adiante de acordo com sua definição de situação. Dúvida e confiança se alternam no hospital, os participantes nas atividades sabem como cambiar de uma a outra.

Não são os objetos distintos que separam as ciências, mas as práticas. Uma diferença importante entre a atuação dos médicos e da antropóloga nesse contexto de prática é que se os primeiros podem alternar entre dúvida e confiança, ela, como antropóloga deve se abster dessa alternação. Sua análise precisa abrir e manter aberta a possibilidade de que as coisas podem ser feitas de outra maneira, isto diz respeito à sua concepção de multiplicidade ontológica. Para ela, a prática médica jamais pode ser tão consolidada e segura de si de modo que não possa ser diferente, a realidade nunca é tão sólida de modo que seja apenas singular, em qualquer circunstância sempre há alternativas possíveis. Não há corpo isolado que possa oferecer um lugar além da dúvida, se os corpos são atuados variadamente, não podem responder sozinhos à questão: o que fazer? A realidade não define de antemão o que se deve fazer, mas a pergunta a ser feita é: com que realidade deve-se viver, pois ela se move e não nos oferece um apoio plenamente seguro. Se a grande questão filosófica acerca da realidade era: como se pode estar seguros a respeito dela? Agora, com a virada para a prática, é: como viver com a dúvida? Como se pode agir em um mundo indeterminado? Se a questão do que fazer não mais depende de um real definido previamente, então, ela depende de que? Ela responde: 
Eu sugiro que se nós não mais podemos nos sentir seguros ao perguntar este conhecimento é verdadeiro com relação ao seu objeto, vale mais a pena perguntar essa prática é boa para os sujeitos (humanos ou outros) envolvidos nela? Se uma representação fiel não mais sustenta o poder de fundamentar-nos, nós podemos ainda buscar intervenções positivas. Portanto, ao invés da verdade devemos, nos orientar pelo bem (goodness). Ou melhor, não o bem como se existisse uma única versão dele, mas bens (goodnesses). (Mol, 2002, p. 165-166)

Aqui ela já assinala claramente que falar em realidades múltiplas implica claramente em se manter no âmbito da ontologia, mas este já não pode ser considerado como algo distinto da ética ou da política, como instâncias que definiriam não o que as coisas são, mas como devem ser.

Acontece que o reconhecimento de que a medicina está entrelaçada com o bem ou bens possíveis conduz frequentemente à questão da chamada a autonomia do paciente. Em favor dos pacientes, argumenta-se que estes, ao invés dos profissionais, devem decidir o que é bom para eles e as escolhas devem ser regidas por suas normas. O papel destinado ao profissional seria apenas o de informar quais são as opções com as quais os pacientes contam, para que possam fazer seu próprio julgamento. Por nesses termos a questão é tentar simplificar algo que é bastante complexo: a decisão acerca do que é bom. Mol se refere a esta concepção de escolha como uma "política do quem". Usualmente esta simplificação corresponde a dois modos de considerar o paciente e sua posição na tomada de decisões. No primeiro caso, utiliza-se o modelo do mercado, em que o paciente é visto como um consumidor prestes a decidir entre produtos postos a sua frente. O médico, por sua vez, faria o papel do vendedor que dá aos pacientes informações sobre os produtos à disposição. É como se cada opção dada pelo médico fosse um bem que pode ser adquirido - comprado - pelo paciente consumidor (independente do fato dele efetivamente pagar pelo serviço ou não). O segundo modo de lidar com a escolha é de caráter cívico. O médico faz intervenções nos modos de vida das pessoas, de modo que se assemelham mais a soberanos que a vendedores. A metáfora cívica envolve uma concepção de paciente em 
que este é visto como um cidadão que merece ter jurisdição sobre as intervenções feitas sobre seu corpo e vida. Decisões são singularizadas, e o paciente tem que ser capaz de argumentar civicamente em favor de um curso de ação ou outro. O paciente cidadão na "política do quem" é uma espécie de representante de si mesmo quando decisões sobre saúde são tomadas. Tanto a metáfora do mercado quanto a cívica têm em comum uma preocupação com quem decide. Ela aponta problemas com essa "política do quem", principalmente, a suposição de que as vontades e desejos das pessoas são formados, claros e determinados fora da situação.

Contra essa política ela argumenta que a questão mais importante pode não ser o quem decide, mas sim o que deve ser feito. O que é o bem em uma situação? Isto nos conduz a outro problema com a "política do quem", ela isola os momentos em que a escolha é feita, separa a tomada de decisão da história que produziu aquela situação. No entanto, vários elementos relevantes para fazer ou desfazer os bens da vida envolvidos na tomada de decisão escapam do momento da decisão.

O terceiro problema com a "política do quem» é a pretensão de reduzir o poder dos profissionais ao reforçar a noção de que a escolha é do paciente. Contudo, o contrário é o que se dá, pois a força dos médicos acaba por ser robustecida na medida em que garante a eles o domínio dos fatos, incumbidos de informar aos pacientes, como se exibissem a eles uma tabela neutra contendo prós e contras de cada opção. Mas que fatos devem ser apresentados? Quais são pertinentes para a realidade da aterosclerose: a da patologia, da clínica etc.? Informação apresenta sempre alguma versão da realidade, que não vem antes da prática, nem depois, mas se entrelaça nela. É um ponto crítico separar fatos e valores, deixar os médicos com os primeiros e os pacientes com os segundos. Latour (2004) já mostrou sobejamente os perigos dessa separação e as dificuldades realtivas à manutenção da divisão que em última instância implica em tomar como universos incomensuráveis fatos e valores, natureza e cultura.

Por isso, para Mol, a questão é menos modificar os limites do poder decisório de médicos e pacientes, mais buscar novos modos de compartilhar o mesmo território. No hospital, a questão mais 
importante não é quem, mas o que fazer. Por isso, ela propõe em lugar de uma "política do quem" uma "política do que".

Para a medicina o que fazer foi sempre uma questão importante e sempre teve reconhecida sua dimensão normativa. Contudo, as normas envolvidas na resposta a essa pergunta foram naturalizadas. Considerase que salvar vidas e melhorar a saúde são sempre desejáveis, são, com efeito, os princípios do que a medicina deve fazer. O valor da vida e da saúde, julga-se, é dado por nossa existência física e é posto acima de qualquer disputa. Usualmente os parâmetros de avaliação das intervenções médicas são dados por medidas quantificáveis de sucesso (no caso da aterosclerose, por exemplo, melhoria nos índices de pressão). Mas em uma "política do quê" esses parâmetros se mostram insuficientes, pois foram estabelecidos em um momento em que os objetivos das intervenções médicas eram considerados como dados pelas características naturais do corpo. Ela pergunta: será que no tratamento de certos tipos de câncer, adiar a morte, a custa de muito sofrimento do paciente, é mesmo sempre a melhor opção? Não há outros caminhos possíveis? Se as alternativas se abrem, a meta da sobrevivência perde sua autoevidência. Ainda que o termo qualidade de vida tenha sido cunhado para preencher o espaço deixado pelo desapontamento das pessoas apenas com a sobrevivência, este termo precisa ainda ser também desnaturalizado. O que é uma boa vida deve ser reconhecido como algo sujeito a contestação e, portanto, como uma questão inerentemente política. Aliás, não é casual que ela tenha usado os termos "política do quem" e "política do que" para dar conta de modos possíveis de lidar com as múltiplas realidades da doença. Política remete aqui à recusa de tratar a realidade como dada e o reconhecimento de que é preciso lidar com multiplicidades.

Para ela justamente, uma "política do que" assume que as metas das intervenções médicas são políticas. "Uma política do que explora não a diferença entre médicos e pacientes, mas entre as várias atuações de uma doença particular" (Mol, 2002, p. 176). E as diferenças entre as atuações implicam diferentes ontologias. Se cada uma faz um corpo diferente, também faz um bem distinto. Assim como o corpo é múltiplo, assim também é o bem. É por isso que o termo política é 
o mais apropriado. A ciência por um longo tempo sustentou, talvez continue a sustentar, o fechamento em termos da apresentação de fatos. Nas instâncias que usualmente se assumem como responsáveis pela ética há, também, ainda que temporariamente, uma promessa de fechamento através da formação de um consenso. Ela tenta romper com essas premissas ao tornar "o que fazer" uma questão política, pois

[...] o termo política evoca abertura, indeterminação. Ajuda a sublinhar que a questão o que fazer não pode ser fechada nem por fatos, nem por argumentos e consensos. O que fazer é uma questão que vem sempre acompanhada de tensões ou dúvidas. Na cosmologia política do que fazer não é um dado na ordem das coisas, mas algo que necessita ser estabelecido. (Mol, 2002, p. 177)

Ela afirma a existência de alternativas e o caráter inerentemente político da decisão sobre o que fazer, não redutível a uma "política do quem", mas para seguir sustentando esse ponto é preciso ainda enfrentar o problema da distinção entre multiplicidade e pluralismo. Há um tipo de pluralismo que se põe contra a ideia de uma verdade única enunciada por especialistas, fala da existência de vários especialistas com diferentes horizontes, nenhum dos quais dotados de objetividade e cada um deles possuiria sua trajetória, habilidades e um olhar diferente, portanto, cada um produziria uma representação também distinta. Aqui há, sem dúvida, uma quebra com a visão monopolística da verdade, mas nesse caso a realidade não se multiplica, apenas os olhares, pois cada perspectiva é exclusiva, discreta, existindo lado a lado em um espaço neutro. Um segundo tipo de pluralismo é o construtivismo, que mostra como uma versão específica da realidade é tecida ao mesmo tempo em que a contesta, bem como desacredita as demais visões alternativas. Um ponto central ao argumento construcionista é que as versões alternativas àquela que efetivamente se consolidou e tronou-se aceita não eram fadadas ao fracasso desde o início, elas foram vencidas em algum momento, em uma história é contingente de luta pelo poder de determinar os fatos (Mol, 1999).

Em qualquer caso, as versões dos fatos são independentes. Mas as diferentes atuações de uma doença apresentadas por ela não são independentes. A medicina é permeada de tensões, mas são raros os 
choques de paradigma. A interdependência entre as diferentes versões de qualquer doença torna "escolha" um termo pouco apropriado para articular a essência da política do que e também para as diferenças nas atuações das realidades. Se as práticas não atuam apenas uma entidade, mas evocam um mundo, então não é apenas a doença que vem em variedade, mas também as pessoas. Nós não temos o domínio - qualquer que seja nossa posição na situação, como médico, paciente, antropólogo - da realidade atuada, mas estamos envolvidos nela. Não há atores independentes situados fora da realidade que pode escolher em favor ou contra ela. Ela propõe outros termos ao invés de escolha: desacordo, tensão, contraste, multiplicidade, interdependência, coexistência. Falar das tensões no hospital não implica em que ele viva em permanente desordem e caos, tensões se cristalizam em padrões de coexistência que só lentamente se dissolvem.

Por fim, é fundamental colocar mais um ponto. Se a ciência não produz uma representação da realidade, mas atua a realidade e intervém no mundo, é preciso considerar que o mesmo se dá com a antropologia. E do mesmo modo que se pode perguntar com relação a outras ciências, é preciso também interrogar se as interferências que resultam dos relatos etnográficos são boas. Como fazer bons relatos? Considerando a afirmativa já apresentada anteriormente, de que as divisões usualmente aceitas entre as ciências e seus objetos não se sustentam, o etnógrafo não pode determinar antecipadamente quais são os tipos de eventos ou objetos relevantes para ele com base no que pertence a sua disciplina ou a outras. Ou seja, as coisas se tornam mais complexas. Além disso, de acordo com Mol, à antropologia cabe sustentar a abertura para outros possíveis. É isto que ela faz no livro, esta é sua forma de atuar e interferir. Mol não se engaja em críticas à medicina mais comuns, por exemplo, de que o poder médico subjuga o paciente e retira dele as suas possibilidades de escolha, já se viu como ela se distancia dessa visão ao não subscrever a prática médica em termos de uma "política do quem". Ele também não traz um conjunto de normas com as quais julgar a medicina, mas se interessa em discernir quais são as normas vigentes na diferentes práticas. Isso não quer dizer, entretanto, que seu relato seja neutro, para ela “[...] há outro modos de parcialidade além do julgamento [...]" (Mol, 2002, 
p. 184), por exemplo, ele interfere ao minar as hierarquias entre as ciências, ao apontar para a persistência das dúvidas, ao dar visibilidade a dimensões que usualmente recebem pouca atenção e ao acentuar a necessidade de uma "política do que", assim ela pretende ajudar a abrir o domínio profissional. Quais serão os efeitos disso, ela não pode saber ao certo, mas, como no caso da medicina, é preciso não deixar que a dúvida nos paralise, mas aprender a viver com a incerteza.

\section{Conclusão}

Falar de uma política ontológica envolve um questionamento acerca dos modos pelos quais o real está implicado no político e viceversa. Se o termo ontologia no sentido mais usual define aquilo que pertence ao real e às condições de possibilidade do nosso viver, como combinar esse termo com política, que em geral aponta para condições de possibilidade que não são dadas? Nessa junção se tece uma realidade que não precede às práticas mundanas, mas que é moldada por elas. O uso do termo política acentua o modo pelo qual se dá esse processo de formação e o fato de que ele é aberto e contestado.

Contudo, por vezes, esse modo de falar de política é considerado como uma maneira de não se pronunciar explicitamente sobre aquela esfera que usualmente é chamada de política, que diz respeito, por exemplo, a instituições e procedimentos específicos, a questões como democracia e representação. Ou seja, como observa Marres (2009), a ontologia é politizada, mas a política não é ontologizada. Embora os estudos de ciência e tecnologia, inclusive os de Mol, tenham contribuído para desestabilizar a noção de sujeito autônomo que está subjacente à concepção de política democrática, não parece ser tão claro como essa atenção concedida à relacionalidade e às agências heterogêneas e distribuídas pode contribuir para reconstruir as instituições políticas.

Ao fazer tal crítica Marres, que não se dirige exclusivamente a Mol, se arrisca a uma aproximação com os intelectuais politicamente engajados que, por terem assumidos antecipadamente a relevância de certos temas ou instituições, censuram em autores que tratam de ontologias múltiplas a falta de tomadas de posições críticas firmes e claras em política. Mol poderia ser acusada, por exemplo, de não 
ter sido crítica o bastante com a medicina. O problema é que quem se coloca na posição de fazer denúncias costuma pensar a realidade em termos de causas e consequências, dominantes e dominados e se põe na posição de quem consegue mais e melhor do que os demais. Mas quando se afirma que a ontologia se faz na prática e que a ação é distribuída entre agentes bastante heterogêneos, as situações se mostram mais complexas e o próprio pesquisador não pode se pôr em uma posição exterior aos problemas dos quais ele trata. Para Mol, a capacidade de seguir a realização do mundo, não dá ao pesquisador um ponto de vantagem ético, no sentido clássico do termo, de ser capaz de apontar para o que está errado e, consequentemente, como a falha deve ser reparada. Mas, trazer a complexidade das práticas não torna a análise menos importante, pois ela pode produzir um efeito perturbador e inquietante, pois, nos relatos, as prática e materialidades, os habitantes dos mundos descritos e suas relações começam a aparecer de modo diferente. O relato etnográfico abre para explorações coletivas situações que são simultaneamente importantes e complexas, pois ninguém pode ter acesso imediato a suas soluções.

Isso coloca em outros termos a questão da responsabilidade, na media em que o pesquisador nunca pode estar seguro acerca do que ele vai encontrar no final e de qual o destino daquilo que ele coloca no mundo. Nesse caso é preciso recolocar a questão da responsabilidade, pois como é possível responder sobre ou prestar contas acerca de algo que não está plenamente sob o controle do cientista? A ética deve ser pensada em uma nova chave, uma chave menor. Nela, o que se demanda é atenção à situação e abertura aos seus possíveis, ao invés de uma adesão a um princípio geral que conferiria o direito de agir. A resposta que precisa ser respondida é: por que você escolheu agir deste modo nesta situação? Que diferenças se pretende incluir no mundo com a sua intervenção? Responsabilidade é uma questão de concernimento (Stengers, 2005, p. 188). A ideia de que é preciso manter a atenção e abertura aos possíveis são aspectos cruciais na proposta de Mol, por isso, ela insiste em uma filosofia empírica, radicalmente etnográfica que não apela aos universais para se justificar, tal exigência a mantém próxima das múltiplas ontologias advogada por antropólogos interessados em manter a abertura do arco dos mundos possíveis. 
Novas ontologias - no plural - emergem sempre no mundo e o uso de termo no plural se justifica, pois se a realidade é feita em muitos contextos locais, ela é múltipla. Por fim, segundo Mol (2002, p. 83), a política ontológica deve "[...] tolerar finais abertos, encarar dilemas trágicos e viver em tensão". Qual a vantagem de adotar essa ontologia que cultiva a dúvida e presta atenção ao modo como a ação é distribuída em diferentes contextos? Isso nos instiga a redescrever a natureza do social, amplia nossa sensibilidade aos diferentes poderes que circulam no mundo, pode conduzir a encontros mais cuidadosos entre pessoas e materialidades (Bennet, 2010).

\section{Notas}

1 Cursou Graduação, mestrado e doutorado em Ciências Sociais na Universidade Federal da Bahia. Fez pesquisas sobre redes sociais e problema mental, prática médica, relação médico paciente e atualmente se dedica a projetos na área de estudos de ciência e tecnologia e relação entre humanos e animais não humanos. Formação: Doutora em Ciências Sociais pela Universidade Federal da Bahia, título obtido em 2014. Vínculo institucional: Professora Associada do Departamento de Sociologia da Universidade Federal da Bahia. Este trabalho foi realizado com o o apoio concedido pelo CNPQ ao projeto "Vidas Experimentais: conhecendo o inexplorado mundo do bioterio e seus habitantes", Processo n. 482129/2011-5.

2 Pode-se dizer que o que distingue os diferentes modos de ser, para Heidegger, é a compreensão, da qual apenas o Dasein é dotado.

\section{Referências}

BENNETT, Jane. Vibrant Matter: a political ecology of things. Durham: Duke University Press, 2010.

BLASER, Mario. Ontology and indigeneity: on the political ontology of heterogeneous assemblages. Cultural Geographies, [S.l.], p. 1-10, 2012. Disponível em: < http://cgj.sagepub.com/content/ early/2012/10/04/1474474012462534>. Acesso em: 18 fev. 2013.

BLOOR, David. Knowledge and social imagery. Londres: Routledge, 1991.

BRAUN, Bruce; WHATMORE, Sarh J. The stuff of politics. In: Political Matter - Technoscience, democracy and politc life. Minneapolis: University of Minnesota Press, 2000. 
CALLON, Michel. Some Elements of a Sociology of Translation: domestication of the scallops and the fishermen os St Brieuc Bay. In: LAW, John. (Org.). Power, action and belief: a new sociology of knowledge? Londres: Routledge, 1986.

\section{CARRITHERS, M. M. et al. Ontology is just another word for} culture. Group Debates in Anthropological Theory (GDAT), 2008. Disponível em: <http://www.socialsciences.manchester.ac.uk/disciplines/ socialanthropology/research/gdat/documents/2008\%200ntology\%20 justanother\%20word\%20for\%20culture.pdf>. Acesso em: 16 aug. 2011.

COLLINS, H. M.; YEARLEY, Steven. Epistemological Chicken. In: PICKERING, Andrew Pickering. (Org.). Science as Practice and Culture. Chicago: The University of Chicago Press, 1992.

HEIDEGGER, Martin. Ser e Tempo. Petrópolis: Vozes, 1988. v. I. HENARE, Amiria; HOLBRAAD, Martin; WASTELL, Sari. Thinking through things: theorising artefacts ethnographically. Londres: Routledge, 2010.

HOLBRAAD, Martin; PEDERSEN, Morten Axel; VIVEIROS de CASTRO, Eduardo. The Politics of Ontology: anthropological positions. Fieldsights

- Theorizing the Contemporary, Cultural Anthropology, on-line, v. 13, January, 2014. Disponível em: < http:/culanth.org/fieldsights/462the-politics-of-ontology-anthropological-positions $>$. Acesso em: 20 maio 2015.

JENSEN, Casper Bruun. A Nonhumanist Disposition: on performativity, practical ontology, and Intervention. Configurations, [S.l.], v. 12, p. 229261, 2004.

KNORR-CETINA, Karin. New developments in science studies: the ethnographic challenge. Canadian Journal of Sociology, [S.l.], v. 8, n. 2, p. 153-177, 1983.

KNORR-CETINA, Karin. Epistemic Cultures: how the sciences make knowledge. Cambridge, MA: Harvard University Press, 1999.

LATOUR, Bruno; WOOLGER, Steve. Vida de Laboratório. Rio de Janeiro: Relume Dumará, 1999.

LATOUR, Bruno. Politics of Nature: how to bring science into democracy. Cambridge: Harvard University Press, 2004.

. Reassembling the Social: an introduction to actor-networktheory. Oxford: Oxford University Press, 2005. 
LYNCH, Michael. Ontography: investigating the production of things, deflating ontology. Social Studies os Science, [S. 1.], v. 43, n. 3, p. 444$462,2013$.

MARRES, Noortje. Testing Powers of Engagement Green Living Experiments, the Ontological Turn and the Undoability of Involvement. European Journal of Social Theory, [S.l.], v. 12, n. 1, p. 117-133, 2009. MOL, Annemarie. Ontological Politics. A Word and Some Questions. In: LAW, John; HASSARD, John. (Org.). Actor network theory and after. Oxford: Blackwell Publishing, 1999.

. The body multiple: ontology of medical practice. Durham: Duke University Press, 2002.

PICKERING, Andrew. The mangle of practice: time, agency \& science. Chicago: The University of Chicago Press, 1995.

STENGERS, Isabelle. Introductory Notes on an Ecology of Practices. Cultural Studies Review, [S.l.], v. 11, n. 1, p. 183-196, 2005. . A Constructivist Reading of Process and Reality. Theory, Culture S Society, [S.l.], v. 25, n. 4, p. 91-110, 2008.

VIVEIROS DE CASTRO, Eduardo and. Manchester Papers. Social Anthropology, [S.l.], v. 7, p. 1-20, 2003.

Recebido em 29/05/2015

Aceito em 04/1 1/2015 